because he was not allowed to be both a mathematician and an engineer, and in 1947 he took a year's leave during which he wrote an influential philosophical paper on artificial intelligence. In this article he disposed of most of the arguments that are made against the possibility of the machine simulation of thought processes. In 1948 he moved to Manchester and produced the programming system for the Manchester University Computer, Mark II.

Turing was logical but emotional, excitable but kind, eccentric but natural, and intellectually and physically strong. He was a very good long-distance runner and

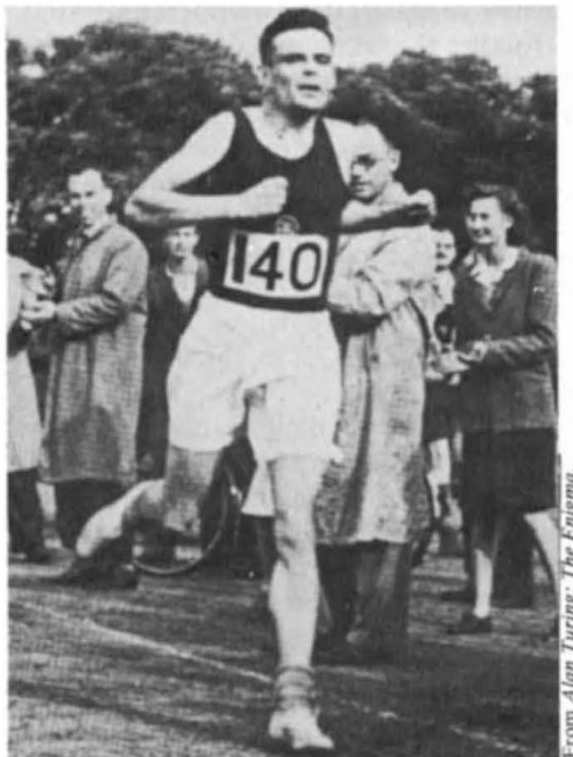

Turing, the runner, in the mid-1940s.

might have run in the Olympic games, but developed a neurological complaint in a leg. After the war he admitted privately that he ran partly to work off libido and that he was a homosexual; fortunately MI5 did not know of his homosexuality during the war. In 1952 he published a seminal contribution to the mathematical theory of growth, but in the same year he was convicted for having a homosexual relationship with a 19-year-old man and was put on probation and on chemical therapy. In June 1954 Turing committed suicide.

In this biography Hodges treats most of these aspects of Turing's life, and many others, and attempts to trace the origins of his ideas in his early environment. The book is researched and written extraordinarily well; I found only a few minor inaccuracies in spite of having known over a hundred of the people mentioned by Hodges. It is a first-class contribution to history and an exemplary work of biography.

1.J. Good is University Distinguished Professor of Statistics at the Virginia Polytechnic Institute and State University, Blacksburg, Virginia. A collection of his writings, Good Thinking: The Foundations of Probability and Its Applications, was published last year by the University of Minnesota Press. During the Second World War, he was Turing's and later M.H.A. Newman's main statistical assistant in cryptanalytic work.

\section{Formats for language development}

John McShane

\section{Child's Talk: Learning to Use}

\section{Language.}

By Jerome Bruner.

W.W. Norton/Oxford University Press: 1983. Pp.144. Hbk \$13.95, £11; pbk $£ 5.95$.

A CHILD must master a complex grammatical system in acquiring language. How he does so has been a central issue of debate and research for the past twenty-five years. Much of the discussion has concerned what sort of unique language-learning capacities human beings might or might not have. However that question is answered eventually, a child would not learn a language without being part of a community of other speakers.

Thus, any reasonably complete answer to the question of language acquisition must give an account of both the child's language-learning capacities and the environmental features that stimulate those capacities. Bruner's book is a summary of a decade of his work on the role of the environment in language acquisition. It is not a general review of research in this area; indeed, there is little mention of some standard issues such as the grammatical characteristics of parental talk to children. Instead, problems that have concerned Bruner during the past decade are examined, considered and summarized. The book provides a clear and illuminating introduction to these concerns but, inevitably perhaps, fails to satisfy one's desire for a thorough-going consideration of the positions of other theorists.

Chapter 2, which deals with the relations between language and non-language, is the clearest example of where more was needed. Bruner makes two points concerning the non-linguistic foundations of language. The first is that language structures have analogues in other areas of cognition. Thus, at least some of the structure of language might be derived non-uniquely. The trouble with this view is that it is notoriously difficult to move from pointing at plausible candidates from which to derive grammatical structures to demonstrating a causal link, as Bruner recognizes. Because he has not set out to write a detailed critical review, these complex issues are finessed. Bruner's other point is that a child is not simply learning grammatical structures in learning a language; he is also learning the conventions for the use of linguistic structures. He argues forcefully that many of these conventions are set-up by the child's social environment, independently of the child's grammatical abilities and usually well in advance of them. The mechanism by which this occurs is the heart of the book.

Bruner argues that adults create structured interactions with children and maintain the basic structure over many months while gradually handing over more and more control of the structure of the interaction to the child. Bruner calls these structures formats. Within a format a child gradually achieves an increasing degree of competence with the adult's aid and cajoling. As competence increases so the adult demands for competence increase. Formats for peekaboo games, reference and requesting are considered in some detail.

Not many researchers have followed Bruner's path of exploring the interaction of adult and child in detail and implicating the structure of the interaction in a causal model of development. To my mind this is a great pity. While this particular tack does not answer all questions about language development, it seems to be a more fruitful approach to the role of the environment than the more common technique of correlating features of parental speech with later features of the child's speech, in complete oblivion of the interactional context in which the speech occurred. The more dynamic approach of Bruner is both timeconsuming and labour-intensive on the part of the researcher. This book makes a sound case for the investment required. $\square$

John McShane is a Lecturer in the Department of Psychology at the London School of Economics and Political Science. He is author of Learning to Talk (Cambridge University Press, 1980).

\section{Control by calcium}

\section{P.F. Baker}

Intracellular Calcium: Its Universal Role as Regulator.

By Anthony K. Campbell.

Wiley: 1983. Pp.556. £36.75, \$79.95.

THE importance of intracellular calcium as a widespread, if not universal, regulator of cell function is well recognized. "Control by calcium" exhibits three key features: maintenance of a very low cytosolic free $\mathrm{Ca}$ in the face of intracellular and extracellular pools of $\mathrm{Ca}$ at much higher concentrations; the presence of special voltage or receptorcontrolled mechanisms for permitting $\mathrm{Ca}$ to enter the cytosol from one or more of these high $\mathrm{Ca}$ pools; and the existence within the cytosol of a special class of $\mathrm{Ca}$ receptor proteins that serve to transduce alterations in free $\mathrm{Ca}$ to changes in enzyme activity and cell function. Despite this apparent simplicity, it is often difficult in practice to unravel the part played by calcium in a particular physiological process and much effort has been expended in trying to develop suitable experimental techniques. The success of this effort is 